\title{
Awareness of the Misconduct in Sports Science Research
}

\author{
${ }^{1}$ Dário Emanuel Proença Gaspar* ${ }^{*}$, 1,2 Marial Dulce Leal Esteves \\ ${ }^{1}$ Department of Sport Sciences, University of Beira Interior, Covilhã, Portugal. ${ }^{2}$ Research Center in Sport \\ Sciences, Health, and Human Development (CIDESD), Department of Sport Sciences, University of Beira \\ Interior, Covilhã, Portugal.
}

Submitted 28 September 2020; Accepted in final form 30 November 2020.

\begin{abstract}
Background. Misconduct in sport science research is a detrimental practice, as it affects data reliability and decreases the validity of all research in the long run. Objectives. The objective of this narrative review is to identify the main problems of misconduct in sport science research and point out effective prevention methods. Methods. A literature search was undertaken in "Web of Science" and "PUBMED" databases, where several terms identified a priori and related to Boolean operators were combined, resulting in a total of 181 records and 19 documents found by crossreferences that were subsequently selected. Results. As a result, we found that most abusive behavior consists of results fabrication, manipulation, and plagiarism. It is noted that, in modern times, there is more pressure on data publication, also, easy Internet access seems to have increased misconduct behaviors. Meanwhile, there are several studies focused on identifying misconduct and ensure research validity, such as students/professors' characteristics; analysis of academic and national procedures; action procedures, and strategies when identified abusive behavior. Conclusion. The present investigation has relapsed a lot on the identification of profiles of researchers who carry out misconduct and have used mostly one methodology, in this case, questionnaires, of which one can question the validity of the answers given due to the susceptibility of the subject itself. Therefore, we believe that the focus of the investigation to solve this problem must be changed and who can answer the following question: how can we identify data manipulation, fabrication, or falsification during its collection or treatment?
\end{abstract}

KEYWORDS: Humans, Plagiarism, Prevention Methods, Publications, Reproducibility of Results, Research Ethics.

\section{INTRODUCTION}

Scientific research is the result of the human need to study, explain, and comprehend our existence and all that surrounds us. Most technological and even social progress is due to scientific discoveries, this states the extreme importance of scientific research to human existence. Vaghri et al. consider that some universities' role in society is to promote scientific research on professional ethics and educate students to become committed citizens, contributing to attend to society's demands (1). This makes misconduct in scientific research a very counter-productive behavior that may endanger all scientific community and prevent it to fulfil their role in society. Various authors agree that academic misconduct is any attempt to gain academic advantage through behavior that may be considered inappropriate by the community (1-5). According to Setamdideh et al., misconduct can be divided into two types, intentional which is characterized by the behaviors referred to below, and unintentional which reflects the authors lack knowledge about the collected references or citations and negligence of the laws/ regulations

*. Corresponding Author:

Dário Emanuel Proença Gaspar, M.Sc.

E-mail: dario.gaspar@ubi.pt 
and the ethical values of scientific research (3). The identified misconduct behaviors are plagiarism; alteration or transcription of existing academic documents; exclusive access to documents or other material that is not yet available for general consultation; help a friend unfairly gaining an academic advantage; the inconvenience of authorship; forging data $(1,6)$.

Considering the above, it comes to our attention that the appearance and development of the Internet have been contributing to the increase in misconduct behaviors $(1,7)$. So, it becomes even more important to identify and prevent this kind of behavior, to maintain valid and reliable data. Most research results suggest that lazier students or the ones working in the field of investigation are more likely to show abusive behavior $(1,3,8)$.

Research has been focused on (a) identifying profiles, nationalities, and regions of common cases of misconduct behaviors, (b) validity of the identification methods, and (c) if those methods are being applied as a means of prevention. Up to date, the community is still unable to answer the referred items and points to the need for more research being made (8). Accordantly, the importance to prevent misconduct in scientific research comes to our attention, urging us to try to identify misconduct behaviors in sport science research and prevention strategies.

Scientific misconduct is a widespread phenomenon that occurs in different countries and is not related to a discipline, university, or country (1, 9). Sports sciences, which create new knowledge about the human movement in sports practice through the integration of knowledge from other disciplinary areas, such as biochemistry, physiology, anatomy, psychology, biomechanics, among others, are also a target of scientific misconduct.

It is important to assess which are the most critical aspects of scientific misconduct in scientific research in sports sciences.

To achieve this goal, we intend to elaborate a narrative review to identify major problems of misconduct in sport science research and point methods to prevent it.

\section{MATERIALS AND METHODS}

Considering the objectives of this study the methodology of the narrative literature review was adopted, which consists of a broad review appropriate "to describe and discuss the development or the 'state of the art' of a given subject, from a theoretical point of view" (10). In this type of review, systematic and exhaustive analyses are not necessary.

Preliminarily, the terms associated with the theme were explored by identifying the keywords of the most relevant articles in the area. The terms contained in a greater number of documents (in the target databases: Web of Science and PUBMED) were combined and related to Boolean operators.

This was followed by the application of research equations (eg, "Sport Science" AND ("Ethical Problems" OR Misconduct OR Plagiarism)), in the aforementioned databases, with the time limit between 2008 and 2019. As research is a dynamic process, other relevant documents (eg, cross-references) have been added.

The exploration and application of the research strategy took place from $08 / 11 / 2019$ to 22/12/2019. In total, 181 records were identified. The extraction of articles was followed by an organization in Mendeley and the elimination of duplicates. Then, the selection phase was carried out by title and abstract and, later, by full text (Figure 1). Considering the objectives of the present work, strict criteria were not applied for the critical evaluation of each result. Review articles, opinions, empirical research, reports, and academic papers that addressed facilitating aspects were included.

The article sought an evaluation of the main types of scientific misconduct, with a particular focus on sports science research. This focus is justified (a) by the inclusion in the keywords used in the narrative review of the term "sports science" and (b) by further deepening the literature that specifically addresses the context of research in exercise or sport. The specific literature on science misconduct in sports science research is scarce, so some of the articles included in the narrative review are not specific to this area. However, the entire review is geared to an application within the scope of sports sciences.

\section{RESULTS}

How to Identify Research Misconduct and Preventions Strategies? In this section, we will 
expose the methods used during the research to identify or evaluate the extent of misconduct behaviors (see Table 1).

Fatima et al. aimed to analyze the internal and external factors of plagiarism and their effects on university students, based on relevant theories and analysis of quantitative and technical research tools (11). For that, questionnaires were used.
Likewise, Jereb et al., evaluated the factors that influence plagiarism, comparing German and Slovenian students, also using questionnaires (7).

Walker, that aimed to provide reliable empirical data on the frequency, nature, and extent of plagiarism, applied a longitudinal study on a sample of 569 students, using "Turnitin" software to identify plagiarized material (8).

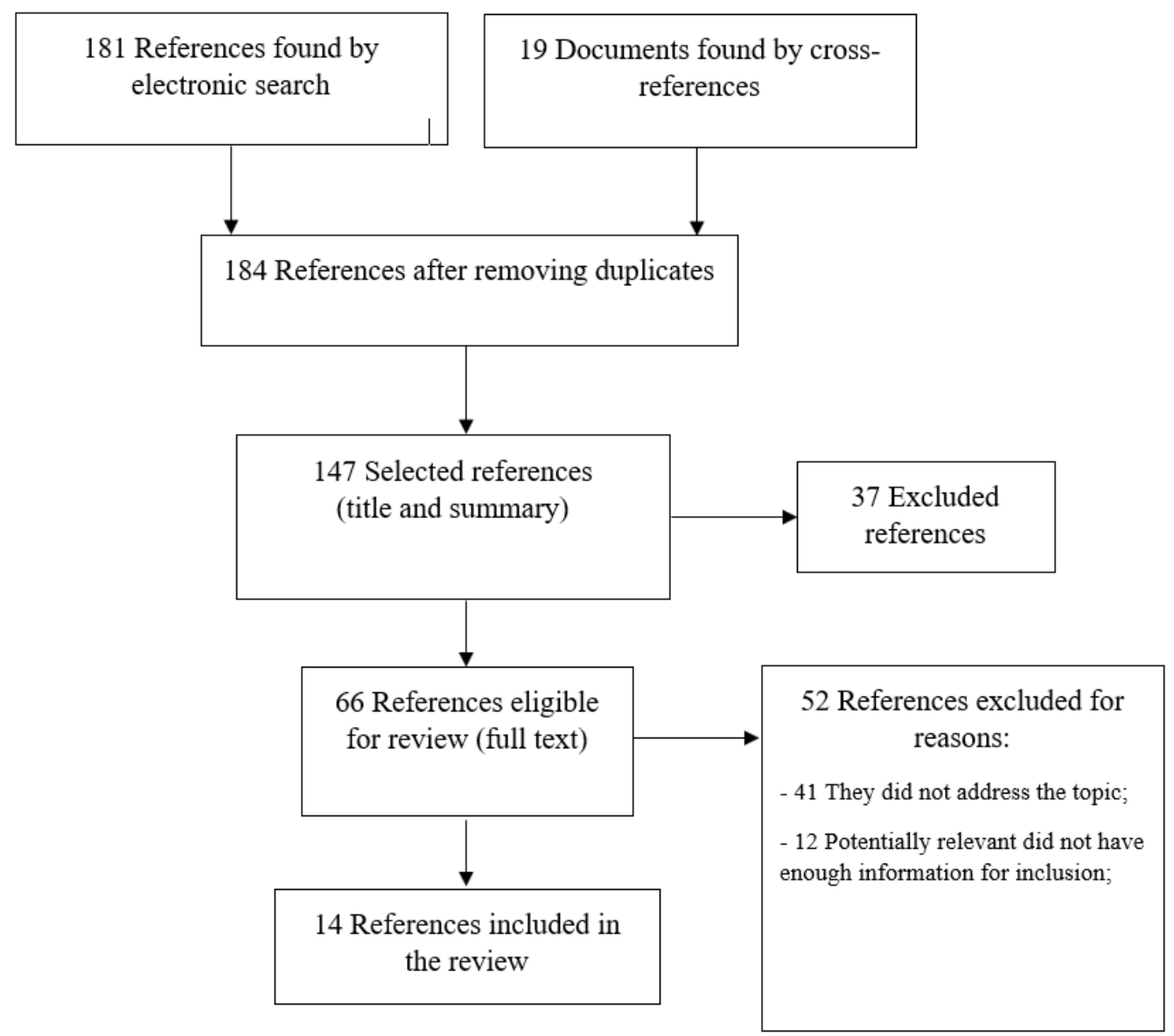

Figure 1. Flowchart of Article Selection

A narrative review was used by Pàmies et al. sought to answer 2 themes: to make known a process structure for managing plagiarism; and, to identify individual characteristics that are determinants of people who perform plagiarism (12). Pupovac and Fanelli carried out a systematic review and meta-analysis to evaluate the prevalence of plagiarism (13). Stavale et al. set to investigate Brazilian academic ethical behavior also performed a systematic review (4).

To determine the impact of the methods of prevention on different types of academic misconduct in sports both Vaghri et al. and Setamdideh et al. used questionnaires $(1,3)$.
Similarly, Pratt et al. and Holtfreter et al. also used questionnaires in their research aim to find possible solutions to the problem of misconduct $(5,14)$.

Considering the above questionnaires are the most common type of procedure to evaluate research misconduct and prevention strategies used. Holtfreter et al. state that questionnaires may not be producing true validity as researchers may be reluctant to participate or are not true when they have to report their behaviors (5). So, is this the correct methodology/path? The other methodology used are literature reviews, but this method only used secondary data. 
Table 1. Summary Table of the Results of the Analysed Articles

\begin{tabular}{|c|c|c|c|c|}
\hline Autor / Year & Title & Methodology & Participants & Key Findings \\
\hline $\begin{array}{l}\text { Boesz, C., \& Lloyd, } \\
\text { N. (2008) }\end{array}$ & $\begin{array}{l}\text { Collaborations: Investigating } \\
\text { international misconduct }\end{array}$ & - & - & $\begin{array}{l}\text { One of the problems identifies is the differences } \\
\text { between assessment systems for misconduct in } \\
\text { international research }\end{array}$ \\
\hline $\begin{array}{l}\text { Fatima, A., Abbas, } \\
\text { A., Ming, W., } \\
\text { Hosseini, S., \& Zhu, } \\
\text { D. (2019) }\end{array}$ & $\begin{array}{l}\text { Internal and External Factors } \\
\text { of Plagiarism: Evidence } \\
\text { from Chinese Public Sector } \\
\text { Universities }\end{array}$ & Questionnaires & 176 China & $\begin{array}{l}\text { That external and internal factors influence } \\
\text { plagiarism. Positive impact: teaching factors; } \\
\text { external stress; pride; lowest academic level; part- } \\
\text { time students }\end{array}$ \\
\hline $\begin{array}{l}\text { Holtfreter, K., } \\
\text { Reisig, M. D., Pratt, } \\
\text { T. C., \& Mays, R. D. } \\
\text { (2019) }\end{array}$ & $\begin{array}{l}\text { The perceived causes of } \\
\text { research misconduct among } \\
\text { faculty members in the } \\
\text { natural, social, and applied }\end{array}$ & Questionnaires & $\begin{array}{l}613 \text { United } \\
\text { States }\end{array}$ & $\begin{array}{l}\text { Conditions that lead to research misconduct: } \\
\text { professional strains and stressors; Insufficient } \\
\text { censure for research misconduct }\end{array}$ \\
\hline
\end{tabular}

$\begin{array}{lc}\text { Jereb, E., Perc, M., } & \text { Factors influencing } \\ \text { Lämmlein, B., } & \text { plagiarism in higher } \\ \text { Jerebic, J., Urh, M., } & \text { education: A comparison of } \\ \text { Podbregar, I., \& } & \text { German and Slovene } \\ \text { Šprajc, P. (2018) } & \text { students. } \\ \text { Krishan, K., } & \text { Plagiarism in Student } \\ \text { Kanchan, T., } & \begin{array}{c}\text { Research: Responsibility of } \\ \text { the Supervisors and }\end{array} \\ \text { Muryah, N., \& } & \text { Suggestions to Ensure } \\ \text { Mukhra, R. (2017) } & \text { Plagiarism Free Research. } \\ \text { Navalta, J., Stone, } & \text { Ethical Issues Relating to } \\ \text { W., \& Lyons, S. } & \text { Scientific Discovery in } \\ \text { (2019) } & \text { Exercise Science. }\end{array}$

(2019) Exercise Science.
The main reason driving plagiarism: easy access to information-communication technologies and the

Web; teaching factor; pressure and pride; men. Don't have differences between German and Slovene students

Suggestions: Anti-plagiarism software in all universities and be part of the curriculum; submit a plagiarism report before your research; maintain awareness programs

Clarify: how to properly identify and reference the authors in an article and address topics such as the researcher's skills, conflicts of interest, honesty, fabrication, or counterfeiting among other matters.

Plagiarism occurs: students know that other colleagues have done so; pressure in time; lack of motivation. Teachers who have had bad experiences are less likely to plagiarize; some studies do not observe gender differences; older, wealthier students plagiarize less. $40 \%$ of teachers had no attitude towards a student who plagiarized

They favored a formal punitive approach to dealing with misconduct; Integrated approach to deal with misconduct was the 2nd most chosen; Female more likely to adopt punitive sanctions; Relieving stress was not so voted

The rate at which scientists report knowing a colleague: who committed plagiarism is higher than for data fabrication and falsification; who committed plagiarism is correlated to that of fabrication and falsification. The rate at which scientists admit having committed either form of misconduct in surveys has declined over time. There were no differences between studies carried out in the USA and other countries, contrary to research that suggests that plagiarism rates are higher in developing countries.

Show the importance of prevention methods, especially the knowledgeable observers and judges;

Suggest that developing and testing reliable methodologies for research on misconduct must be reconsidered.

Plagiarism was the main reason for retraction; following duplicated publication; and error (mainly

Research misconduct in health and life sciences research: A systematic review of retracted literature

Some different $\quad 65$ articles Database Brazilian

Zicker,

M. R. C. G., de

Oliveira, C. M., \&

Guilhem, D. (2019)

Vaghri, M., Memarbashi, A., \&

Mostafapour, M. (2016) from Brazilian institutions

Academic Misconduct:

Categories and Anticipation

Procedures in Physical

Questionnaires

236 Iran Education

in inappropriate statistical analysis, study design, and inadequate data collection); The enforcement of disciplinary and educational measures is fundamental to reduce the incidence of corrupted science

Lack of awareness of the types of misconducts and not being a comprehensive definition from the plagiarism can be very efficient on the incidence of types of scientific misconducts; The prevention ways of its incidence should be found and the new methods are adopted for resolving its reasons Higher plagiarism rate in International students; Older students. Profile of a student who practices

Measuring plagiarism: Researching what students do, not what they say they do.
Questionnaires $\quad 569 \mathrm{New}$

Zealand plagiarism: male or female, an international student, studying internally, aged 21-30, and possibly in the fourth year of enrolment at the university. Turnitin did not prove to be a barrier to plagiarism. 
Identification and Procedures to avoid Misconduct. The integrity of the research is based on rigorous methodological approaches, and those practices known to hinder certain stages are classified as misconduct in research (4). That reality exists and is not confined to a discipline, university, or country, but instead spread on a global scale (1). It is a problem that the scientific community cannot afford to neglect because it is gaining certain proportions that denigrate the image of scientists and universities, calling into question all research (2). Economically, it is estimated that billions of dollars have been wasted to finance studies based on non-accepted publications (4). It should be noted that scientific organizations (Universities and Research personnel) whose existence heavily depends on the quality and reliability of studies carried out have an even greater interest in reducing misconduct to preserve its integrity. In this sense, the next step of the prevent review was to look for reasons for misconduct, establish the individual characteristics of the offenders, and to understand the procedures to be adopted in their identification. However, regarding it, no concrete references were found in sports science research. This misconduct behavior may be intentional or not intentional (3). Regarding nonintentional practices, they are related to the lack of knowledge of the ethical values of scientific research on the part of some young researchers (1). Navalta et al. aiming to present concepts related to ethical issues in conducting scientific research, clarify, how to properly identify and reference the authors in an article, and address topics such as the researcher's skills, conflicts of interest, honesty, fabrication or counterfeiting among other matters (6). Vaghri et al., with their study, concluded that the use of the Internet or certain applications are increasing the falsification of documents (1). To eliminate such practice, they suggest that, rather than strengthening the current rules, it is important to give more training courses, seminars, and conferences, and that advisors and judges should have more control.

Regarding intentional practice and considering the results of the Holtfreter et al. one of the reasons that are strongly linked to research misconduct has to do with the pressure exerted on education and research facilities to publish their work in journals with a high impact factor (5). This often happens as a result of certain external financing. Consequently, it creates data fabrication, manipulation, falsification, and plagiarism (4).

\section{DISCUSSION}

Regarding the plagiarism, according to Fishman and the study by Jereb et al., it is most common when someone: (a) uses words, ideas, or work products; (b) attributable to another person or identifiable source; (c) without identifying the source where it was obtained; (d) in a situation where there is a legitimate expectation of original authorship; (e) to obtain any benefit, credit, or gain even if not a monetary one (7). Jereb et al. also consider that plagiarism can be practiced intentionally in a perspective of gaining time (efficiency), family and social pressures to obtain a good grade, fear of failure, laziness, and simply "because everyone does it" (7). For these reasons, plagiarism in research has been the subject of many studies. Krishan et al. consider plagiarism as a serious threat that ravages world scientific research. Especially among young researchers, there is a growing need to address the plagiarism issue, particularly in the most developed countries of the world (15).

Searching for a profile of the investigators who practices plagiarism, Pàmies et al. characterized their study group: a) by gender (male or female) and they identify that was many studies found that males are more likely to plagiarise than females; b) nationality and this can be due to cultural nuances, the educational system, and social factors, not identifying the nationality that practices more plagiarism; c) age, between 21 and 30, the older the lesser the tendency to practice plagiarism; d) and possibly attending the fourth year of enrolment at the university (12). However, they also mention that there is a lot of controversy regarding the identification of an exact profile.

More than identifying a profile, it is important to identify and report this behavior. Walker et al. questioned if the use of Turnitin software was a suitable tool to prevent plagiarism (8). As a result, it was found that this was important in detecting plagiarism, but that the same program was known to students and that they used it to get around such a situation. A recent study by Pàmies et al. found that $40 \%$ of investigation teachers took no action when faced with cases of plagiarism in the student community (12). The reasons they point to are: additional workload to proceed with the consequences; important emotional reasons for 
not acting, such as lack of courage or stress to face such a situation; concerned with the image and professionalism in denouncing someone under their tutelage; and in some cases, the teachers feel that the institution does not support them sufficiently in these cases.

Thus, given the reasons previously mentioned, it seems to us that there is a barrier when it comes to acting towards misconduct behavior in the investigation. Guiding Professors, Universities, Journals, and Reviewers have a very important role in the intervention and prevention of research misconduct. Pupovac and Fanelli suggest that developing and testing reliable methodologies for research on misconduct must be reconsidered (13).

\section{CONCLUSION}

Present work aimed to elaborate a narrative review to identify major problems of misconduct in sport science research and point methods to prevent it. The major conclusion is the lack of research on the extension of science misconduct in sports science research. It would be important to make a more in-depth assessment of the main problems and their extent in this area of research.

Some of the other conclusions refer to scientific misconduct in general areas, that are common to sport sciences research. It seems that the investigation has relapsed a lot on the identification of profiles of researchers who carry out misconduct and have used mostly one methodology, in this case, questionnaires, of which one can question the validity of the answers given due to the susceptibility the subject itself. Therefore, we believe that the focus of the investigation to solve this problem must be changed.

One of the first steps, considering that students have tutors for counseling/guidance, is the tutor's duty to familiarize students with the ethical values in scientific research and to make known the implications and consequences when there is misconduct. In this sense, the role of the tutor is fundamental and must make sure he leads by example.

Due to the global dimension of the problem and the differences between systems of misconduct assessment, the role of the University in preventing misconduct is of the most importance. These, as macrostructures, must support and defend the interests of the research professors when it comes to denouncing these behaviors, as it seems to us that, with the increased pressure of "doing more and better" with financial objectives, the scientific truth is sometimes being put aside. Therefore, another important step, and since these behaviors are often identified, would be to analyze and clarify the reasons why misconduct in the scientific community is not being reported. These are our suggestions to improve/create a standardized method that ensures the discussion of ethical policies, promotes a uniform publication where anyone who identified misconduct could denounce it without being afraid of reprisals.

In conclusion, we may say that this review focused a lot on plagiarism in the scientific community, but another important issue came to our attention as we reviewed the available literature: how can we identify data manipulation, fabrication, or falsification during its collection or treatment?

\section{APPLICABLE REMARKS}

- It was evident in this narrative review the lack of research on the extension of science misconduct in sports science research. It would be important to make a more in-depth assessment of the main problems and their extent in this area of research.

- Given the results of this narrative review, it is concluded that to reduce the extent of scientific misconduct in the area of sports sciences, two strategies must be followed: (a) Include in the academic program (master's or doctoral) program contents that address ethical issues in scientific research and (b) The need to establish codes of conduct that identify the main practices of academic misconduct and the sanction to which the practitioner must be subjected.

- This investigation highlighted the role of the tutor in demanding compliance with ethical requirements in the research process he is supervising, denouncing abusive behaviors, and direct the investigation to why those behaviors are not often reported.

\section{FUNDING}

This work is financed by national funds through FCT - Foundation for Science and Technology, I.P., under the project UIDB / 04045/2020.

\section{CONFLICT OF INTEREST}

The authors declare that they have no conflict of interest. 


\section{REFERENCES}

1. Vaghri M, Memarbashi A, Mostafapour M. Academic Misconduct: Categories and Anticipation Procedures in Physycal Education. Eur J Phys Educ Sport Sci. 2016;2(5).

2. Boesz C, Lloyd N. Collaborations: investigating international misconduct. Nature. 2008;452(7188):686687. doi: 10.1038/452686a pmid: 18401384

3. Setamdideh M, Memarbashi A, Ghaderi L. Prevetion Methods and Types of Academic Miscounduct. Eur J Phys Educ Sport Sci. 2016;2(1).

4. Stavale R, Ferreira GI, Galvao JAM, Zicker F, Novaes M, Oliveira CM, et al. Research misconduct in health and life sciences research: A systematic review of retracted literature from Brazilian institutions. PLoS One. 2019;14(4):e0214272. doi: 10.1371/journal.pone.0214272 pmid: 30986211

5. Holtfreter K, Reisig MD, Pratt TC, Mays RD. The perceived causes of research misconduct among faculty members in the natural, social, and applied sciences. Stud High Educ [Internet]. 2019;0(0):1-13. doi: 10.1080/03075079.2019.1593352

6. Navalta J, Stone W, Lyons S. Ethical Issues Relating to Scientific Discovery in Exercise Science. Int J Exerc Sci. 2019;12(1):1-8.

7. Jereb E, Perc M, Lammlein B, Jerebic J, Urh M, Podbregar I, et al. Factors influencing plagiarism in higher education: A comparison of German and Slovene students. PLoS One. 2018;13(8):e0202252. doi: 10.1371/journal.pone.0202252 pmid: 30096189

8. Walker J. Measuring plagiarism: Researching what students do, not what they say they do. Stud High Educ. 2010;35(1):41-59. doi: 10.1080/03075070902912994

9. Artino AR, Jr., Driessen EW, Maggio LA. Ethical Shades of Gray: International Frequency of Scientific Misconduct and Questionable Research Practices in Health Professions Education. Acad Med. 2019;94(1):76-84. doi: 10.1097/ACM.0000000000002412 pmid: 30113363

10. Rother ET. Revisão sistemática X revisão narrativa. ACTA Paul Enferm. 2007;20(2):6-7. doi: 10.1590/S0103-21002007000200001

11.Fatima A, Abbas A, Ming W, Hosseini S, Zhu D. Internal and external factors of plagiarism: Evidence from Chinese public sector universities. Account Res. 2018. doi: 10.1080/08989621.2018.1552834 pmid: 30477348

12.Pàmies $\mathrm{M}$ del $\mathrm{M}$, Valverde $\mathrm{M}$, Cross $\mathrm{C}$. Organising research on university student plagiarism: a process approach. Assess Eval High Educ [Internet]. 2019;0(0):1-18. doi: 10.1080/02602938.2019.1658714

13.Pupovac V, Fanelli D. Scientists Admitting to Plagiarism: A Meta-analysis of Surveys. Sci Eng Ethics. 2015;21(5):1331-1352. doi: 10.1007/s11948-014-9600-6 pmid: 25352123

14.Pratt TC, Reisig MD, Holtfreter K, Golladay KA. Scholars' preferred solutions for research misconduct: results from a survey of faculty members at America's top 100 research universities. Ethics Behav [Internet]. 2019:1-21. doi: 10.1080/10508422.2019.1612748

15. Krishan K, Kanchan T, Baryah N, Mukhra R. Plagiarism in Student Research: Responsibility of the Supervisors and Suggestions to Ensure Plagiarism Free Research. Sci Eng Ethics. 2017;23(4):12431246. doi: 10.1007/s11948-016-9822-x pmid: 27896604 